\title{
Early detection of tick-borne encephalitis virus spatial distri- bution and activity in the province of Trento, northern Italy
}

\author{
Annapaola Rizzoli ${ }^{1}$, Markus Neteler ${ }^{1,2}$, Roberto Rosà ${ }^{1}$, Walter Versini ${ }^{3}$, Antonio Cristofolini ${ }^{3}$, \\ Marco Bregoli', Alan Buckley ${ }^{5}$, Ernest A. Gould ${ }^{5}$ \\ ${ }^{1}$ Centre for Alpine Ecology, Viote del Monte Bondone, 38040 Trento, Italy; ${ }^{2}$ Centre for Scientific and \\ Technological Research, via Sommarive 18, 38050 Povo, Trento, Italy; ${ }^{3}$ Occupational Medicine Unit, \\ Health Care Trust (APSS), Province of Trento, Italy; ${ }^{4}$ Istituto Zooprofilattico delle Venezie, Sezione di \\ Trento, via Lavisotto, 38100 Trento, Italy; ${ }^{5}$ Centre for Ecology and Hydrology, Mansfield Road, Oxford \\ OX1 3SR, UK
}

\begin{abstract}
New human cases of tick-borne encephalitis (TBE) have recently been recorded outside the recognised foci of this disease, i.e. in the province of Trento in northern Italy. In order to predict the highest risk areas for increased TBE virus activity, we have combined cross-sectional serological data, obtained from 459 domestic goats, with analysis of the autumnal cooling rate based on Moderate Resolution Imaging Spectroradiometer (MODIS) land surface temperature (LST) data. A significant relationship between finding antibodies against the virus in serum (seroprevalence) in goats and the autumnal cooling rate was detected, indicating that the transmission intensity of the virus does not only vary spatially, but also in relation to climatic factors. Virus seroprevalence in goats was correlated with the occurrence of TBE in humans and also with the average number of forestry workers' tick bites, demonstrating that serological screening of domestic animals, combined with an analysis of the autumnal cooling rate, can be used as early-warning predictors of TBE risk in humans.
\end{abstract}

Keywords: tick-borne encephalitis virus, Ixodes ricinus, early-warning, risk assessment, spatial analysis, MODIS, land surface temperature, autumnal cooling, serology.

\section{Introduction}

Tick-borne encephalitis (TBE) is an emerging tickborne zoonosis caused by a Flavivirus. The Western European subtype (WTBE) of this virus, transmitted mostly by bites of the tick Ixodes ricinus, has been identified in a number of foci across central, western and eastern Europe. It has shown marked heterogeneity, both with reference to spatial distribution and to incidence in humans (Zanotto et al., 1995;

\footnotetext{
Corresponding author:

Annapaola Rizzoli

Centre for Alpine Ecology

Viote del Monte Bondone

38040 Trento, Italy

Tel. + 390461 939555; Fax + 390461921490

E-mail: rizzoli@cealp.it
}

Randolph et al., 2000; Gould et al., 2001; Mickiene et al., 2001; Randolph, 2001; Gritsun et al., 2003; Golovljova et al., 2004). The southern range of TBE virus distribution in Europe includes northern Italy where 131 human cases were diagnosed during the period 1975-2004 (Amaducci et al., 1976; Verani et al., 1995; Hudson et al., 2001; Cinco et al., 2004). Currently, most human cases of TBE are recorded in the north-eastern regions of Italy, in particular in the regions of Trentino Alto Adige, Veneto and Friuli Venezia Giulia (Cruciatti et al., 2006; Floris et al., 2006).

In the province of Trento, where the disease has been recognised since 1992, although with low incidence, an average of 0.6 cases/100,000 inhabitants/year for the period 1992-2004 (Hudson et al., 2001), most of the cases recorded up to the year 
2000 were spatially clustered within the Lake Valley. Recently, however, cases of TBE have been associated with other new foci in this province. Although the TBE virus is usually transmitted to humans through the bite of an infected tick, it may also be transmitted through the consumption of infected (unpasteurised) milk of goats, sheep and cows (Khol et al., 1996; Labuda et al., 2002; Juceviciene, 2005). These animals acquire the infection from infected ticks when grazing in endemic sites. The infection is usually asymptomatic but it occasionally causes diseases in dogs, cows, sheep and goats exhibiting a symptomatology corresponding to that of meningoencephalitis. Experimental inoculation of the virus in adult sheep results in a viraemia that may last up to five days, with shedding of the virus in the milk from the second to the seventh day (Gresikova et al., 1975). In experimentally infected goats, the virus is detected in the milk between the nineth to the twelveth day post-infection but there is no detectable viremia (Labuda et al., 2002). Haemagglutination-inhibiting (HI) antibodies, detected on day 14, decline to half this level in 10 months (Labuda et al., 2002). Although the TBEV is present in the milk of infected animals, thus representing a source of alimentary infection for humans, there is no evidence that large animals such as goats, cattle, roe deer, etc. support virus transmission to ticks, even if they seroconvert following exposure to the virus (Labuda et al., 2002).

A series of epidemiological and virological studies have demonstrated that the TBE virus circulates more actively in areas where a combination of biotic and abiotic factors favours coincidental feeding of $I$. ricinus larvae and nymphs on rodent hosts, especially on the yellow-necked mouse Apodemus flavicollis, thus permitting the non-systemic transmission of the virus through co-feeding ticks. This transmission mechanism affords a greater degree of virus amplification than the conventional viraemic route of transmission. The synchronous feeding activity of larvae and nymphs occurs mainly in areas where a rapid decrease in daily autumnal temperature (rapid autumnal cooling) delays the host- seeking activity of summer-borne larvae favouring a behavioural diapause until the following spring, when they reactivate and co-feed with nymphs (Labuda et al., 1993, 1997; Randolph et al., 1996, 1999, 2000; Labuda and Randolph, 1999).

The aim of this work was to assess the current distribution of TBE foci in the Italian province of Trento by combining serological screening in domestic goats with remotely-sensed climatic data. The aim was also to identify areas where TBEV circulates more actively, which would provide an earlywarning system for veterinary and public health authorities at the local level.

\section{Materials and methods}

\section{Study area}

The study was carried out in the province of Trento, a mountainous region covering an area of $6200 \mathrm{~km}^{2}$ located in north-eastern Italy (centroid coordinates: $11.21 \mathrm{E}, 46.10 \mathrm{~N}$ ). The climate is temperate-oceanic and $70 \%$ of the territory lies above $1,000 \mathrm{~m}$ above see level and $55 \%$ is covered by coniferous and deciduous forests. The fauna includes the majority of recognized species in the Alps, including large vertebrate, as the roe deer (Capreolus capreolus) and the red deer (Cervus elaphus), that act as feeding hosts for $I$. ricinus. In addition, there are rodents, such as the yellow-necked mouse (A. flavicollis) and the bank vole (Clethrionomys glareolus), that both attract ticks and can act as amplifying hosts of TBE virus (Randolph et al., 2002). Spatial distribution, relative abundance and seasonal activity of the tick I. ricinus have been assessed in previous studies (Merler et al., 1996; Rizzoli et al., 2002).

\section{Data collection}

To identify the area where TBE virus circulates more actively, we tested the sera of resident domestic goats that grazed on pastures during summer 2001, for the presence of antibodies against TBE 
virus. We selected goats for this study since they are long-lived, susceptible to TBE virus infection and are usually left to graze in ecotonal areas that represent a suitable habitat for the questing activity of the tick I. ricinus. Goat serum samples were collected by the local Veterinary Hygiene and Public Health Agency during the ordinary surveillance activity. Pasture locations were identified with a questionnaire presented to farmers, and geo-referenced on a web-GIS database. The locations of these grazing areas are shown in Figure 1.

Data on the TBE incidence in humans and number of tick bites recorded on forestry workers in the various valleys of the province during 2001 were provided by the Occupational Medicine Unit, Health Care Trust of the Province of Trento.

\section{Serology}

Plaque reduction neutralization tests (PRNTs) were performed on goat sera as described by Buckley et al. (2003). In order to ensure maximum sensitivity, the PRNT was performed using a $50 \%$ endpoint for plaque reduction neutralization of virus $\left(\mathrm{PRNT}_{50}\right)$. Serial twofold dilutions of sera commenced from a 1:10 dilution.

\section{Climatic data and cooling maps}

To predict the pattern of I. ricinus emergence from diapause during the year 2001 when the goats analysed in this study were left to graze on pasture and subsequently examined for seroconversion, we used remote sensing data from satellite. Following the methodology proposed by Randolph et al. (2000), we analysed the autumnal temperature decline in the year 2000 since the temperature variation in this period might affect the synchronous activity of I. ricinus larvae and nymphs during the following spring (Randolph et al., 2000). Autumnal cooling was calculated to describe the autumnal temperature decline from August to October, relative to the annual maximum of the monthly mean land surface temperature (LST) level in midsummer (northern hemisphere).

We obtained a time series of Moderate

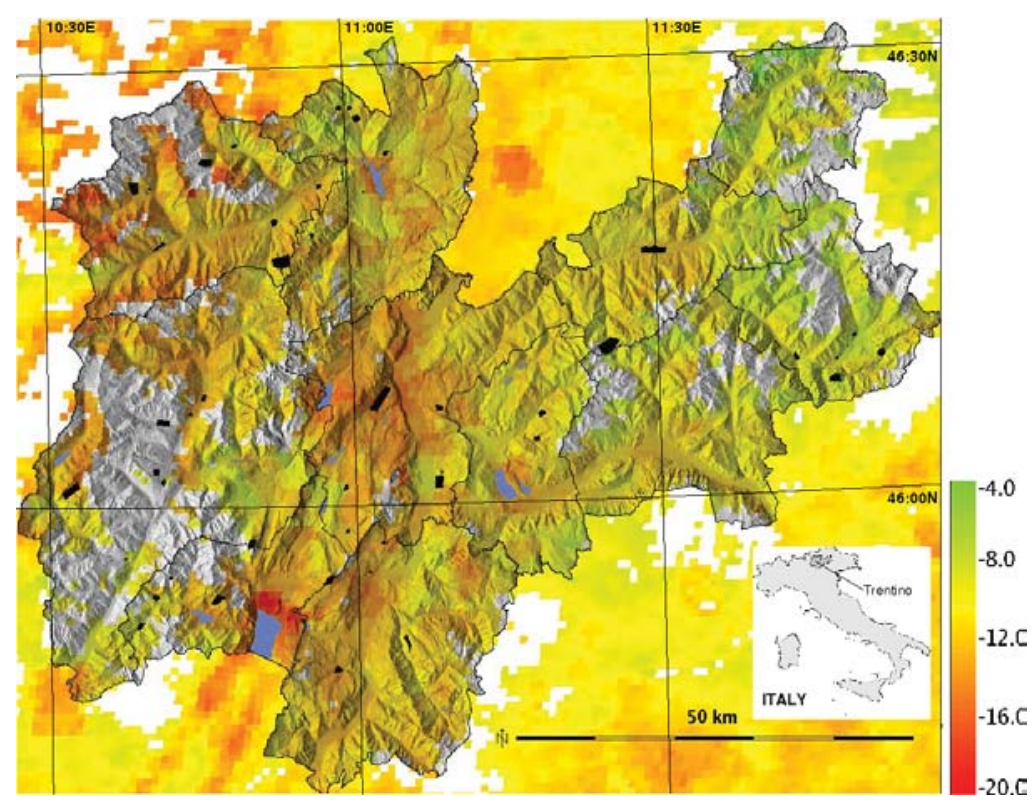

Fig. 1. The location of pastures (black areas) used by goats sampled for TBE virus seroconversion during 2001. The degree of autumnal cooling recorded in Trentino during 2000 is represented as a colour scale from red (rapid cooling) to green (slow cooling). White patches represent "high-cloud contamination", i.e. cooling estimates could not be obtained. 
Resolution Imaging Spectroradiometer (MODIS) LST (level V004) data through the NASA EOS Data Gateway <http://edcimswww.cr.usgs.gov/pub/ imswelcome/>. For the year 2000, we processed data from the Terra satellite which is accessible twice daily (about 10:30, and 22:30, local time). From May 2002 onwards, further two LST images per day were available from the Aqua satellite (about 13:30, and 01:30, local time). The original LST data were provided in Kelvin at a resolution of $1 \mathrm{~km}^{2}$ in Sinusoidal projection. The MODIS LST data pre-processing included a re-projection to the Italian Gauss-Boaga cartographic system, the application of the bit-pattern encoded MODIS quality assurance (QA) maps to filter out poor-quality pixels and to convert Kelvin degrees to centigrades (Celsius). An additional outlier/cloud detector was applied to eliminate remaining cloud-contaminated pixels not discovered by the NASA QA algorithms that were used for producing the LST maps. It is based on a simple histogram analysis to find and remove pixels which show unusually low LST values (Neteler, 2005). Individual MODIS images may also contain areas devoid of data due to the filtering (high-altitude areas covered by snow and ice were not considered as these areas are not relevant for this study). These areas were not closed by means of geostatistics due to the complexity of the terrain of the study sites. Also, since the pixel-wise time series of 3 months daily LST data were individually aggregated to single cooling values, irregular patterns without data and noise were sufficiently compensated.

To calculate the fall in autumnal temperature, we applied linear regression to the monthly LST mean values of August, September and October of the year 2000. In addition we selected the annual maximum of the monthly mean LST values per pixel. The cooling rate is the relationship between this fall in temperature and the maximum LST value. Finally, we calculated the mean cooling rates for the goat pasture locations in centigrades from the LST pixels belonging to each pasture polygon. Linear regression was chosen to take the mean temperature of September into account as the behavioural dia- pause of the tick is driven by temperature characteristics of all autumnal months, not only the difference in temperature between August and October; in case of a relatively warm September this leads to delayed autumnal cooling while a relatively cold September leads to increased autumnal cooling. The entire procedure was implemented in GRASS GIS 6 and R-stats (Neteler, 2005).

\section{Statistical analysis}

To investigate if the TBE virus seroprevalence recorded in the goats was significantly affected by the cooling rate recorded in each pasture location, a generalized linear model (GLM) with a binomial error distribution was performed (S-PLUS, 6.2 Version, Insightful $\left.{ }^{\circledR}\right)$. The TBE virus seroprevalence, estimated as $\mathrm{PRNT}_{50}$, was used as the response variable, while the valley of pasture location and cooling rate were selected as the fixed explanatory variables.

To analyse the relationships between TBE virus seroprevalence in goats and infection risk for humans, expressed as the occurrence of human cases of TBE in each valley, and the average number of tick bites on forestry workers during 2001, a GLM with a binomial error distribution was performed. In this analysis, the TBE virus seroprevalence in goats was used as the response variable, while the occurrence of human TBE cases in the area and the average tick bites on forestry workers, which were protected by vaccination, were selected as fixed explanatory variables.

\section{Results}

A total of 459 goat sera were collected from the 11 major valleys of the province of Trento. The TBE virus seroprevalence, recorded as $\mathrm{PRNT}_{50}$, ranged from 0 to $41.9 \%$ with a mean of $12.0 \%$ (S.E. = $1.5 \%)$. Seropositive goats were found in all the valleys investigated but with a significant variation in infection prevalence $\left(\chi^{2}=38.53\right.$, df $\left.=10, \mathrm{p}<0.01\right)$. The highest value of seroprevalence recorded was in goats left to graze within the Valley of the Lakes 
Table 1. The TBE virus seroprevalence (based on PRNT $_{50}$ tests) in goats sampled from the principal valleys of the province of Trento in Italy during 2001, with the mean cooling rate recorded on the pastures during 2000. The tick bites are entered as the average number of bites found in all forestry workers tested in each valley, while the occurrence of TBE in the resident population is shown as either infected or not.

\begin{tabular}{|c|c|c|c|c|c|c|}
\hline $\begin{array}{l}\text { Valley } \\
\text { investigated }\end{array}$ & $\begin{array}{l}\text { Number of } \\
\text { goats tested }\end{array}$ & $\begin{array}{l}\text { PRNT test } \\
\text { positive }(\%)\end{array}$ & $\begin{array}{l}\text { Standard } \\
\text { error }(\%)\end{array}$ & $\begin{array}{l}\text { Mean cooling } \\
\text { rate }\left(\mathrm{C}^{\circ}\right)\end{array}$ & $\begin{array}{l}\text { Average tick } \\
\text { bites }\end{array}$ & $\mathrm{TBE}$ in residents \\
\hline ADIGE & 40 & 20.0 & 6.3 & -12.10 & 2.46 & Yes \\
\hline CHIESE & 15 & 0.0 & 0.0 & -9.52 & ND & No \\
\hline FIEMME & 78 & 9.0 & 3.2 & -11.43 & ND & No \\
\hline LAGHI & 43 & 41.9 & 7.5 & -12.10 & 3.84 & Yes \\
\hline LEDRO & 52 & 1.9 & 1.9 & -9.83 & ND & No \\
\hline MOCHENI & 23 & 0.0 & 0.0 & -11.06 & ND & No \\
\hline $\mathrm{NON}$ & 22 & 13.6 & 7.3 & -10.83 & 3.07 & Yes \\
\hline PRIMIERO & 12 & 16.7 & 10.8 & -9.61 & 1.75 & No \\
\hline RENDENA & 38 & 7.9 & 4.4 & -12.00 & 2.07 & No \\
\hline SOLE & 127 & 10.2 & 2.7 & -11.56 & 3.00 & No \\
\hline VALLARSA & 9 & 0.0 & 0.0 & -10.52 & ND & No \\
\hline TOTAL & 459 & 12.0 & 1.5 & -11.28 & 2.88 & ND \\
\hline
\end{tabular}

$\mathrm{ND}=$ no data

(Valle dei Laghi), the traditional TBE hotspot, followed by the Adige Valley and Non Valley where most of the new human cases have recently been reported. The details of the data, stratified by valley, are summarized in Table 1.

The cooling rate recorded for the year 2000 in the province of Trento within 36 pasture locations used by the goats for grazing during the spring and summer season of the year 2001 varied from $-8.7^{\circ} \mathrm{C}$ to $-14.68^{\circ} \mathrm{C}$. The TBE virus seroprevalence was significantly affected by the cooling rate of each pasture location, with a significant increase in seroprevalence with the degree of cooling rate $\left(\chi^{2}=9.41, \mathrm{df}=1\right.$, $\mathrm{p}<0.01)$. Not surprisingly, the highest degree of cooling was recorded for the Lake Valley, the traditional TBE hot spot of the province of Trento.

A positive relationships among TBE virus seroprevalence in goats both with the occurrence of disease in humans $\left(\chi^{2}=13.76, \mathrm{df}=1, \mathrm{p}<0.01\right)$ and with the average number of tick bites recorded by foresty workers $\left(\chi^{2}=5.81, \mathrm{df}=1, \mathrm{p}<0.02\right)$ in the same valleys, was observed.

The map of the cooling rates recorded in the province of Trento during 2000 is shown in Fig. 1 together with the location of the pastures grazed by goats in 2001.

\section{Discussion}

We have examined the relationship between autumnal cooling rate and infection seroprevalence for TBE virus in goats in the province of Trento in northern Italy, where recent human cases of TBE have been associated with new foci of this emerging tick-transmitted disease. Although the incidence of disease in humans in this area is low compared to other regions (on average 0.6 cases/100,000 inhabitants/year for the period 1992-2004), the analysis of the serological data collected from the resident goats indicate that the geographic distribution of this virus seems to be widespread in this area. Indeed, the occurrence of TBE virus seropositive goats was detected in many of the territories which were previously catalogued as suitable habitats for I. ricinus in this province (Merler et al., 1996; Rizzoli et al., 2002).

To identify the areas with the highest potential risk of TBE virus infection, we analysed the relationships between TBE virus seroprevalence in goats and the autumnal cooling rate recorded in the same area during the previous year when the goats were left to graze and then exposed to tick bites. This study identified spatial variation in 
TBE virus infection risk in relation to climatic variability with a significant relationship between autumnal cooling and prevalence of infection in goats. Furthermore, the analysis showed a positive relationship between TBE virus seroprevalence in goats and the human potential risk of infection, estimated by the occurrence of clinical TBE cases in the resident population and by the average number of tick bites in forestry workers from the same area.

Previous work, carried out at the continental scale in Europe, have shown that TBE virus foci are characterised by a high rate of autumnal cooling that promotes a specific pattern of $I$. ricinus seasonal dynamics, namely seasonal feeding-synchrony of larvae and nymphs, that facilitates virus transmission through co-feeding on rodents (Labuda et al., 1993, 1997; Randolph et al., 1996, 1999, 2000; Labuda and Randolph, 1999). As expected from the model presented by Randolph et al. (2000), we found a significant increase in TBE virus seroconversion in goats with the increased autumnal cooling rate.

In the Lake Valley, the natural TBE foci of the province, the cooling rate recorded during the year 2000 ranged between $-10.48^{\circ} \mathrm{C}$ and $-14.68^{\circ} \mathrm{C}$; a range that we also observed in other areas where TBE virus does not appear to circulate, at least according to our current knowledge. Indeed, in the natural TBE virus sites we also observed the highest rate of seroconversion in goats. These data indicate that in alpine areas, where climatic variability is high, the predictive value of the cooling rate alone is not sufficient to predict TBE virus circulation and intensity of transmission. However, in such cases, the prediction power can be improved by utilizing also other variables, such as the rate of seroconversion in tick hosts. In this connection, the goat appears to be a useful and cheap sentinel host for estimating TBE virus circulation and intensity of transmission, although goats are not directly involved in virus amplification (Labuda et al., 2002). Indeed, as we have demonstrated in correspondence to TBE virus natural foci, the seroprevalence in goats can be as high $(41 \%)$ as in other domestic animals (Labuda et al., 2002). These results indicate that, in order to avoid human infection through the alimentary route, there is a need to improve veterinary surveillance by including tests for the TBE virus in milk and milk products.

In conclusion, we have examined the spatial variation on the risk of TBE virus infection in the Italian province of Trento, combining remotely-sensed climatic data with serological data collected from goats. This methodology appears useful for the identification of the spatial variation in TBE virus circulation and intensity of transmission but the approach needs to be improved finding more powerful predictors of tick density and tick infection prevalence. The data collected as part of this study indicate that, although the number of human cases of disease is small compared with other neighbouring regions and other European countries, TBE virus is widespread and actively persists in the study area. The next step would be to analyse in detail how other factors, such as the temporal and spatial distribution of tick hosts, may affect TBE virus circulation and infection risk.

\section{Acknowledgements}

This project was supported by the Research Fund of the Autonomous Province of Trento, under Grant 1060 ECODIS. This research was partially funded by EU grant GOCE2003-010284 EDEN and the paper is catalogued by the EDEN Steering Committee as EDEN0039 (http://www.edenfp6project.net/). EAG was supported by the EU $6^{\text {th }}$ Framework Programme VIZIER. RR was supported by the Autonomous Province of Trento under Grant no. 3479 MOSTWIN. All animal handling procedures were carried out in accordance with the protocols approved by the Scientific Committee of the Research Fund of the Autonomous Province of Trento. We thank Dr. Massimo Danielli and the Veterinary Service of the Health Care Trust (APSS) of the province of Trento for their valuable help in goat sera and data collection. The authors also thank the Editor and anonymous reviewers for providing suggestions that led to an improved version of the paper. 


\section{References}

Amaducci L, Arnetoli G, Inzitari D, Balducci M, Verani P, Lopes MC, 1976. Tick-borne encephalitis (TBE) in Italy: report of the first clinical case. Riv Patol Nerv Ment 97, 77-80.

Buckley A, Dawson A, Moss SR, Hinsley SA, Bellamy PE, Gould EA, 2003. Serological evidence of West Nile virus, Usutu virus and Sindbis virus infection of birds in the UK. J Gen Virol 84, 2807-2817.

Cinco M, Barbone F, Grazia Ciufolini M, Mascioli M, Anguero Rosenfeld M, Stefanel P, Luzzati R, 2004. Seroprevalence of tick-borne infections in forestry rangers from northeastern Italy. Clin Microbiol Infect 10, 1056-1061.

Cruciatti B, Beltrame A, Ruscio M, Viale P, Gigli GL, 2006. Neurological manifestation of tick-borne encephalitis in North-Eastern Italy. Neurol Sci 27, 122-124.

Floris R, Altobelli A, Boemo B, Mignozzi K, Cinco M, 2006. First detection of TBE virus sequences in Ixodes ricinus from Friuli Venezia Giulia (Italy). New Microbiol 29, 147-150.

Golovljova I, Vene S, Sjolander KB, Vasilenko V, Plyusnin A, Lundkvist A, 2004. Characterization of tick-borne encephalitis virus from Estonia. J Med Virol 74, 580-588.

Gould EA, De Lamballerie X, Zanotto PM, Holmes EC, 2001. Evolution, epidemiology and dispersal of flaviviruses revealed by molecular phylogenies. Adv Virus Res 57, 71-103.

Gresikova M, Sekeyova M, Stupalova S, Necas S, 1975. Sheep milk-borne epidemic of tick-borne encephalitis in Slovakia. Intervirology 5, 57-61.

Gritsun TS, Nuttall PA, Gould EA, 2003. Virus epidemiology, ecology and emergence. Tick-borne flaviviruses. In: Chambers TJ, Monath TM editors. The Flaviviruses: current molecular aspects of evolution, biology, and disease prevention. Adv Virus Res 60, 318-360.

Hudson PJ, Rizzoli A, Rosà R, Chemini C, Jones LD, Gould EA, 2001. Tick-borne encephalitis virus in northern Italy: molecular analysis, relationships with density and seasonal dynamics of I. ricinus. Med Vet Entomol 15, 304-313.

Juceviciene A, Zygutiene M, Leinikki P, Brummer-Korvenkontio H, Salminen M, Han X, Vapalahti O, 2005. Tick-borne encephalitis virus infections in Lithuanian domestic animals and ticks. Scand J Infect Dis 37, 742-746.
Kohl I, Kozuch O, Eleckova E, Labuda M, Zaludko J, 1996. Family outbreak of alimentary tick-borne encephalitis in Slovakia associated with a natural focus of infection. Eur J Epidemiol 12, 373-375.

Labuda M, Eleckova E, Lickova M, Sabó A, 2002. Tickborne encephalitis virus foci in Slovakia. Int $\mathrm{J}$ Med Microbiol 291, 43-47.

Labuda M, Jones LD, Williams T, Nuttal P, 1993. Enhancement of tick borne encephalitis virus transmission by tick salivary gland extracts. Med Vet Entomol 7, 193-196.

Labuda M, Kozuch O, Zuffova E, Eleckova E, Hails RS, Nuttal PA, 1997. Tick-borne encephalitis virus transmission though ticks co-feeding on specific immune natural rodent hosts. Virology 235, 138-143.

Labuda M, Randolph SE, 1999. Survival strategy of tickborne encephalitis virus: cellular basis and environmental determinants. Zentralbl Bakteriol 289, 513-524.

Merler S, Furlanello C, Chemini C, Nicolini G, 1996. Classification tree methods for analysis of mesoscale distribution of Ixodes ricinus in Trentino, Italian Alps. J Med Entomol 33, 888-893.

Mickiene A, Vene S, Golovljova I, Laiskonis A, Lindquist L, Plyusnin A, Lundkvist A, 2001.Tick-borne encephalitis virus in Lithuania. Eur J Clin Microbiol Infect Dis 20, 886-888.

Neteler M, 2005. Time series processing of MODIS satellite data for landscape epidemiological applications. Int J Geoinformatics 1, 133-138.

Randolph SE, 2001. The shifting landscape of tick-borne zoonoses: tick-borne encephalitis and Lyme borreliosis in Europe, 2001. Phil Trans R Soc Lon B 356, 1045-1056.

Randolph SE, Chemini C, Furlanello C, Genchi C, Hails RS, Hudson PJ, Jones LD, Medley G, Norman RA, Rizzoli A, Smith J, Woolhouse MEJ, 2002. The ecology of tick-borne infections in wildlife reservoirs. In: Hudson PJ, Rizzoli AP, Grenfell BT, Heesterbeek H, Dobson AP (Eds). The ecology of wildlife diseases, Oxford University Press, 119-138 pp.

Randolph SE, Gern L, Nuttal PA, 1996. Co-feeding ticks: epidemiological significance for tick borne pathogens transmission. Parasitol Today 12, 472-479.

Randolph SE, Green RM, Peacey MF, Rogers DJ, 2000. Seasonal synchrony: the key to the tick-borne pathogen transmission. Parasitology 121, 15-23.

Randolph SE, Miklisova D, Lysy J, Rogers DJ, Labuda M, 
1999. Incidence from coincidence: patterns of tick infestations in rodents facilitate transmission of tick-borne encephalitis virus. Parasitology 118, 177-186.

Rizzoli A, Merler S, Furlanello C, Genchi C, 2002. Geographical information system and boostrap aggregation (Bagging) of tree-based classifiers for Lyme disease risk pre- diction in Trentino, Italian Alps. J Med Entomol 39, 485-493. Verani P, Ciufolini MG, Nicoletti L, 1995. Arbovirus surveillance in Italy. Parassitologia 37, 105-108.

Zanotto De A, Gao GF, Venugopal K, Gritsun TS, Marin S, Jiang WR, et al. 1995. An RNA virus cline across the Northern Hemisphere. Virology 210, 152-159. 